\title{
Anatomical and Histopathologic Analysis of Placenta in Dilation and Evacuation Specimens
}

\author{
Taha M. M. Hassan1, Ahmad M. S. Hegazy ${ }^{2 *}$, Mohammed M. Mosaed ${ }^{3}$ \\ ${ }^{1}$ Pathology Department, Bani-Sowif University, Bani-Sowif City, Egypt \\ ${ }^{2}$ Anatomy Department, Benaha Faculty of Medicine, Benha University, Banha City, Egypt \\ ${ }^{3}$ Anatomy Department, Al-Azhar Faculty of Medicine, Al-Azhar University, Assuit City, Egypt \\ Email: ahmed0562301954@yahoo.com
}

Received 18 December 2013; revised 7 January 2014; accepted 20 January 2014

Copyright (C) 2014 by authors and Scientific Research Publishing Inc.

This work is licensed under the Creative Commons Attribution International License (CC BY). http://creativecommons.org/licenses/by/4.0/

(c) (i) Open Access

\begin{abstract}
Background: Anatomical and histopathologic examination of placenta in cases of abortion is crucial as to clarify the underlying causes of many adverse pregnancy outcomes. Dilation and evacuation (D\&E) is the most common mode of uterine evacuation that commonly examined in pathology sections. The aim of this study is to discuss the various placental pathologies, and to demonstrate the importance of careful pathologic examination of D\&E material, also to review the anatomy of placenta and to compare our findings with other publications worldwide. Material and Methods: A retrospective descriptive study for 200 placental tissues was collected in 18 months period and revised for normal anatomy and various placental pathologies. These placentas were obtained by dilation and evacuation (D\&E) technique. All cases were undergone for histopathological sections that were stained by Hematoxylin and Eosin (H\&E). Results: Placental infarction was observed in $\mathbf{2 5 \%}$ of cases, and chorioammnitis was the most common form of placental infection and found in $\mathbf{1 2 . 5 \%}$. Molar changes were represented a lowered percentage of placental pathologies that found in 9\% of specimens. Conclusion: Study and recognition of placental lesions among general surgical pathologists have clinical significance and awareness of deficiency, standardization of diagnostic criteria, and increased knowledge in placental pathology improve the quality of diagnosis in this area.
\end{abstract}

\section{Keywords}

Anatomical, Histopathologic, Placenta, Abortion

\footnotetext{
"Corresponding author.
} 


\section{Introduction}

Placenta is an organ that facilitates nutrient and gas exchange between the maternal and fetal compartments. It has two components: fetal portion, formed by the chorion frondosum and maternal portion, formed by the decidua basalis. On the fetal side, the placenta is bordered by the chorionic plate and on its maternal side, and it is bordered by the decidua basalis, of which the decidual plate is most intimately incorporated into the placenta [1]. This organ has dual blood circulation, functioning throughout fetal development. Placental trophoblasts express and produce coagulation components, participating not only in haemostasis but also in placental vascular development and differentiation [2].

The chorionic villi are the functional unit of placenta and provide oxygen and nourishment to fetus and also serve as excretory unit [3].

The histological appearance of chorionic villi varies with the gestational age and with the stage of development and maturations of villous tree but there is a basic villous structure that is independent of these variables. A trophoblastic mantle that consists of 2 layers, an outer layer of syncytiotrophoblast and an inner layer of cytotrophoblast covers the outer surface of the villi [4].

Abortion is the most common complication of pregnancy. Fifteen percent of recognized pregnancies terminate in spontaneous abortion. There may be many more abortions in early and unrecognized pregnancies [5].

Histopathological examination of the placenta following a pregnancy loss or neonatal death may provide an explanation of the pregnancy complications, pregnancy loss or neonatal death and may also provide information relevant to the management of the current infant and/or subsequent pregnancies and medicolegal litigation [6].

\section{Material and Methods}

Two hundred placental specimens were examined in this study. These placentas were appropriate for gestational age (AGA) and were obtained by dilation and evacuation (D\&E) technique. All these cases were collected from the Department of Pathology, Arar Central Hospital (ACH), Saudi Arabia in 18 months period from April 2012 through November 2013. The cases were reviewed for any placental pathologies using standardized criteria according to [7] [8]. Also, the review diagnosis was compared with the original reports.

All the cases were seen in the obstetrics and gynecology outpatient clinics in Northern Borders Region General Hospitals, KSA. Clinical data that were provided from the patients records revealed that patients were came complaining from vaginal bleeding with low backache after past history of pregnancy. After examination, Dilation and evacuation procedure (D\&E) was done. This procedure is performed as an inpatient surgical maneuver. It begins with a period of preoperative cervical preparation to obtain adequate cervical dilation which is accomplished by use of prostaglandin analogue and it is performed under general anesthesia [8] [9].

The placental tissue is evacuated using a combination of suction and extraction forceps in multiple passes. The obtained placental material is immediately fixed in $10 \%$ formaldehyde, and sent for preparation of formalin fixed paraffin embedded blocks and tissue sections with 3 micron thickness were prepared. All the slides were stained by routine Hematoxylin and Eosin stains (H\&E) then evaluated by 2 experienced pathologists for various types of placental lesions.

\section{Results}

\subsection{Clinical Findings}

The patient's age ranged from 17 years to 40 years with a mean age 27 years (Graph 1$)$. The gravity (G) ranged from G1 to G13, whereas the parity (P) ranged from P0 to P10, and the number of abortions (A) ranged from A1 to A3. Among our cases, spontaneous abortion was observed in 50 cases (25\%), incomplete abortion in 85 cases (42.5\%), septic abortion in 17 cases (8.5\%), abortion following trauma in 10 cases (5\%), unexplained abortion in 20 cases (10\%), and intrauterine fetal death (IUFD) was seen in 18 (9\%) (Table 1).

\subsection{Histopathological Findings}

Microscopic examination of placental specimens revealed the normal appearing fetal villi were separated by clear or blood containing spaces (the intervillous space) where the maternal blood circulates around them, and their sizes vary depending on the gestational age. These villi consist of an outer layer of syncytiotrophoblastic cells in immediate contact with the maternal blood in the intervillous space, and a deeper single, discontinuous 


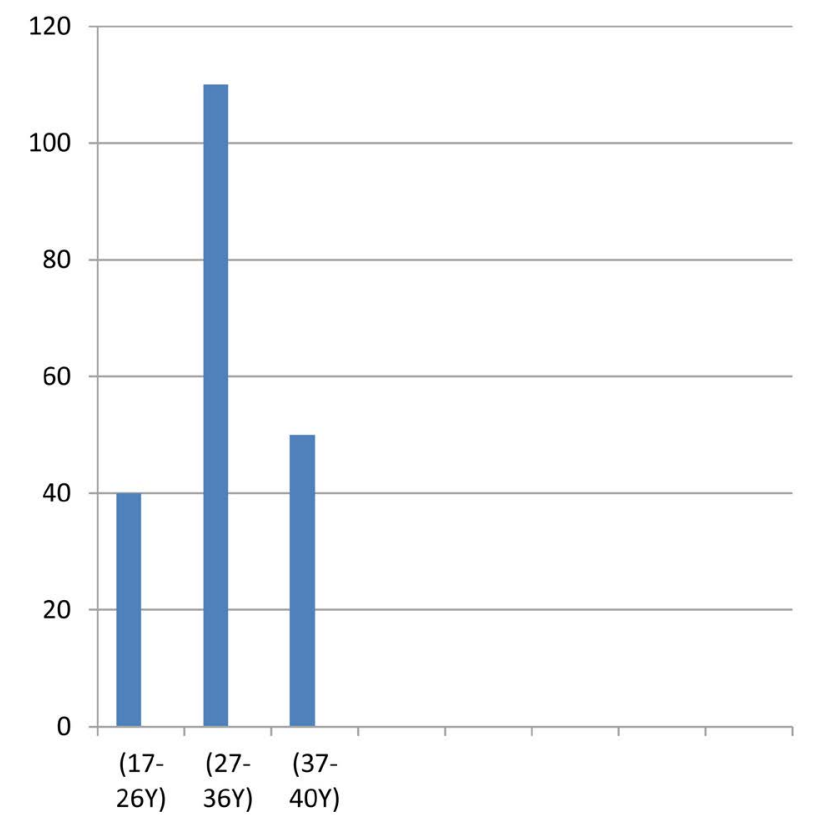

Graph 1. Showing distribution of age groups in all cases studied.

Table 1. Revealing frequency of abortiontypesin all cases studied.

\begin{tabular}{ccc}
\hline Types of Abortion & Number of cases & \% \\
\hline Spontaneous & 50 & 25 \\
Incomplete & 85 & 42.5 \\
Septic & 17 & 8.5 \\
Traumatic & 10 & 5 \\
Unexplained & 20 & 10 \\
Intrauterine fetal death & 18 & 9.5 \\
\hline
\end{tabular}

layer of cytotrophoblastic cells which are larger, and cuboidal (Figures 1-4).

In addition to the above, histopathological examination revealed variable types of placental pathologies which need clarification and documentation in the pathology report. Among these pathologies areas of placental infarction that observed in $25 \%$ of cases (Figure 5). Fortunately these infarcts were focally. Placental infection was seen in $10 \%$ among all placental specimens, majority were chorioammnitis $(7.5 \%)$, whereas villitis with inflammation inside chorionic villi found in $2.5 \%$ of cases. In addition to the above pathologies, perivillous hemorrhages and fibrin deposition seen in $7.5 \%$ of placental pathologies and in some cases they were extensive (Figures 6-8). In the same theme minor areas of placental chorioangiosis were found in $2.5 \%$ (Figure 9). As well as deposition of calcified material in the processed placental tissue was seen in 12.5\% (Figure 10). Small areas of intervillous fibrinoid necrosis in association with the vascular villi were found in 2.5\% of cases (Figure 11) also, necrotic villi and/or avascular villi were appeared in $5 \%$ placentae. Another pathology along our cases was decidualized reaction that seen in association with secondary changes of the endometrial glands in $25 \%$ of cases (Figure 12). Nevertheless most of these changes repeated in conjunction with either ghosts of chorionic villi or in association with trophoblastic elements even after re-cutting or re-grossing of the placental specimens. Other lesion was seen in our cases was hydropic changes that seen in 5\% of cases (Figure 13). Molar changes with trophoblastic proliferation were found in 5\% of placental specimens (Figure 14 and Figure 15) (Table 2).

\section{Discussion}

Pathologic examination of D\&E specimens has been understudied. However, the available literature and experience support the fact that careful pathologic examination of these can identify significant placental as well as fetal changes that can confirm clinical diagnoses, and provide definitive diagnosis from the clinical differential diagnostic lists [8]. 


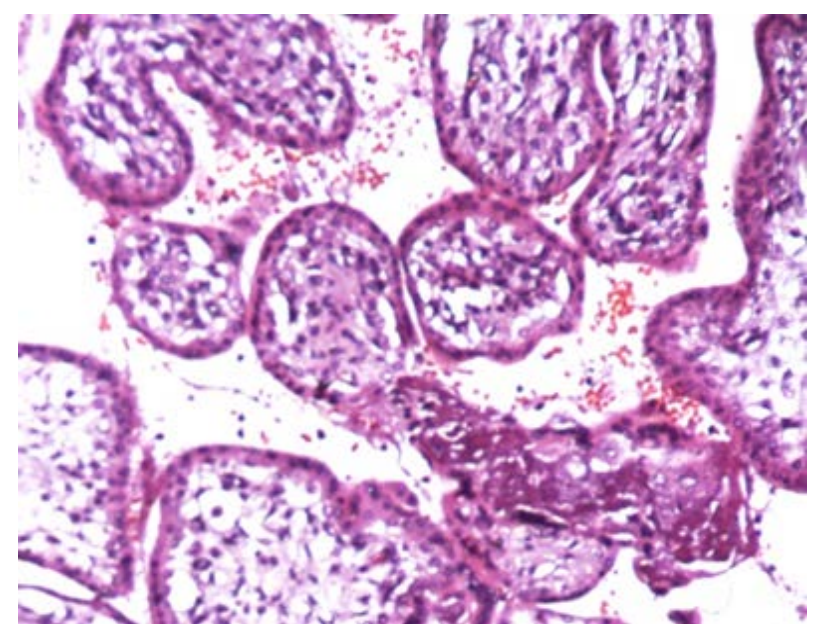

Figure 1. A case of D\&E exhibiting normal chorionic villi with covering trophoblastic epithelium (H\&E 200 X).

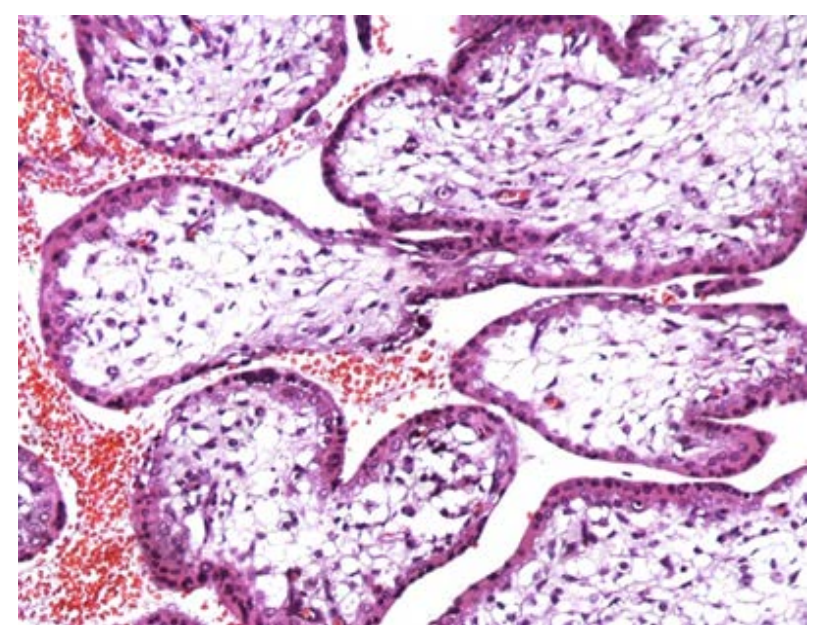

Figure 2. A case of D\&E showing normal cores of chorionic villi with normal trophoblastic lining (H\&E 200 X).

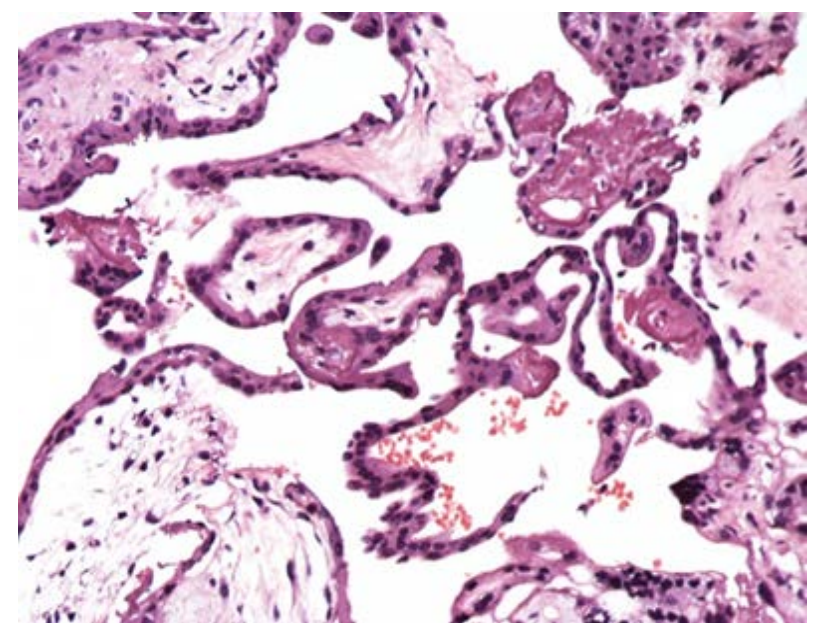

Figure 3. A case of D\&E revealing normal trophoblastic epithelial lining (H\&E $200 \mathrm{X})$. 


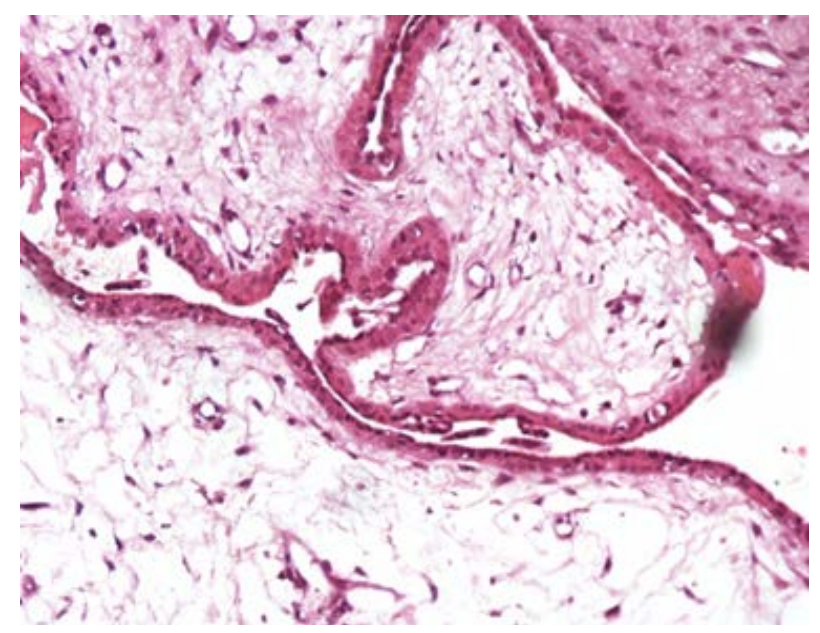

Figure 4. A case of D\&E showing normal villi cores, trophoblastic lining and portion of fetal membrane (H\&E $200 \mathrm{X}$ ).

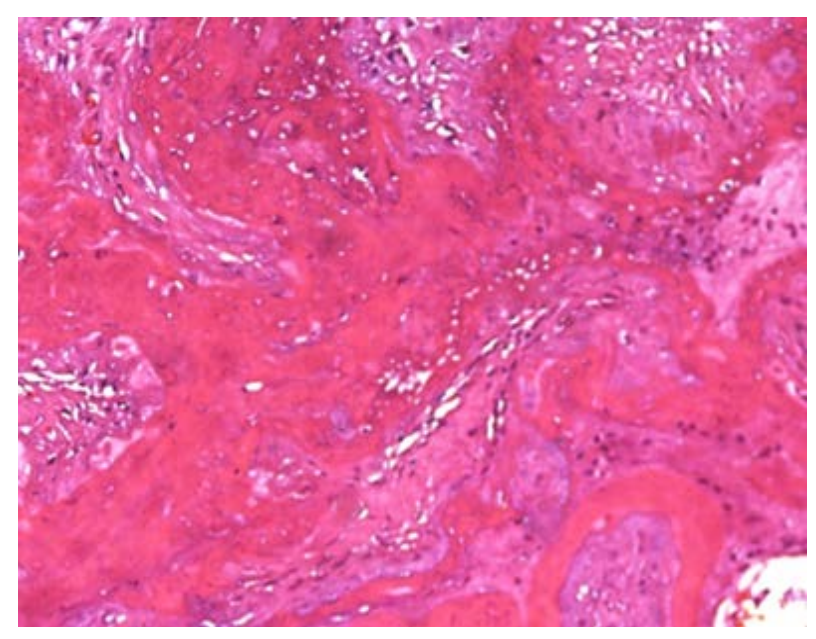

Figure 5. A case of D\&E revealing areas of infarction and ghosts of chorionic villi (H\&E $200 \mathrm{X}$ ).

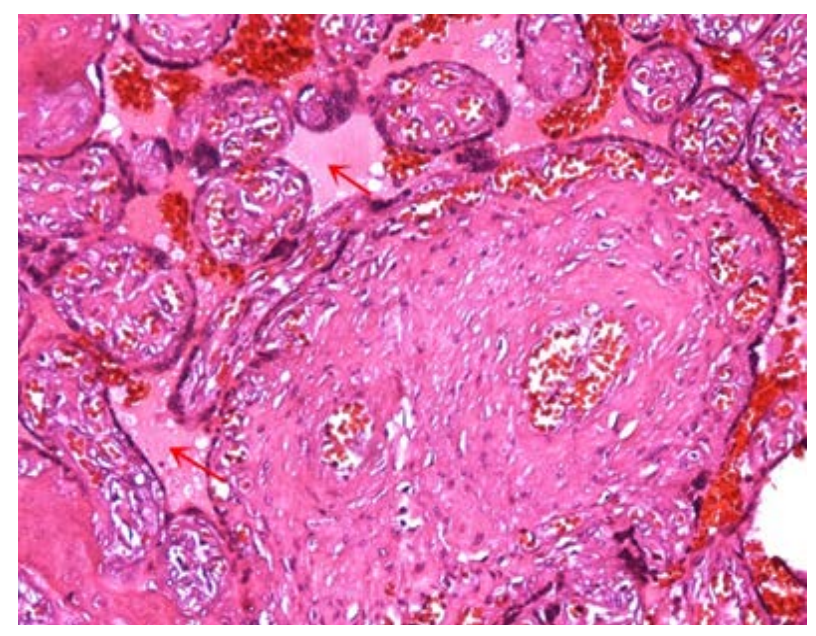

Figure 6. A case of D\&E exhibiting focal perirvillous hemorrhage and fibrin deposition (red arrow) (H\&E $100 \mathrm{X}$ ). 


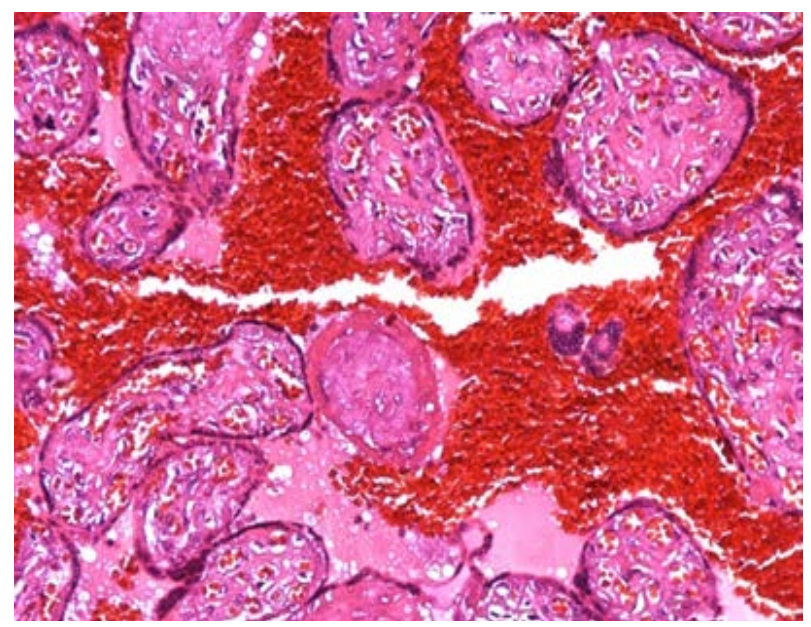

Figure 7. A case of D\&E showing extensive perivillous hemorrhage and fibrin deposition (H\&E $100 \mathrm{X}$ ).

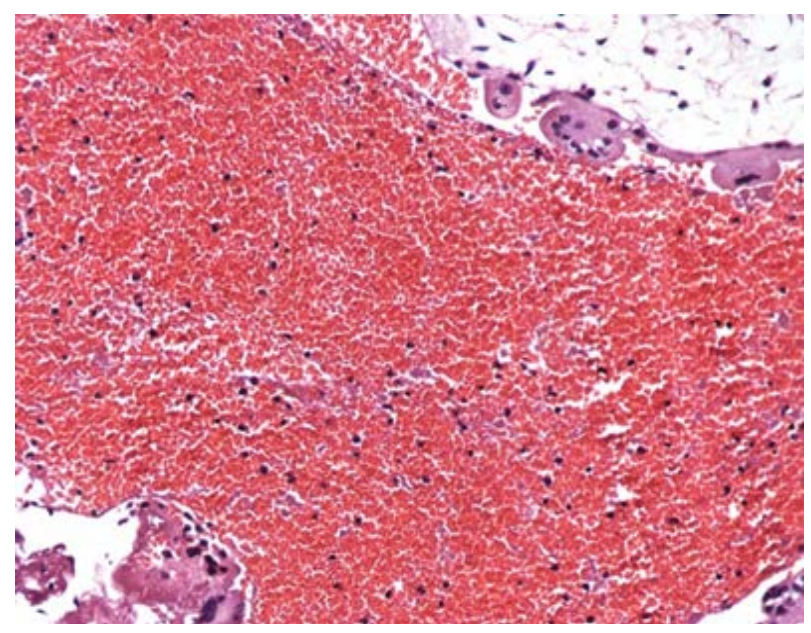

Figure 8. A case of D\&E revealing marked perivillous hemorrhage along with focal trophoblastic proliferation (H\&E $200 \mathrm{X}$ ).

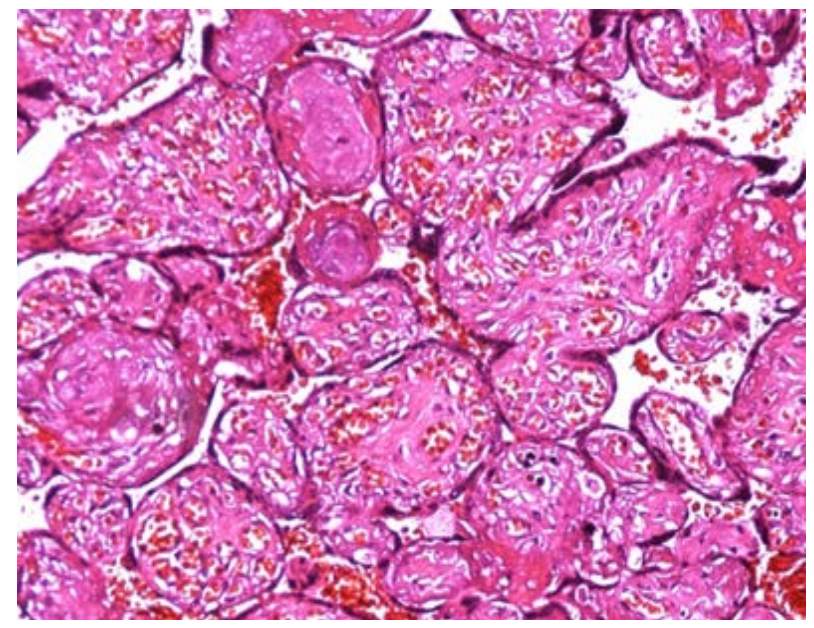

Figure 9. A case of D\&E showing chorioangiosis with intravillous variable sized capillaries (H\&E $100 \mathrm{X}$ ). 


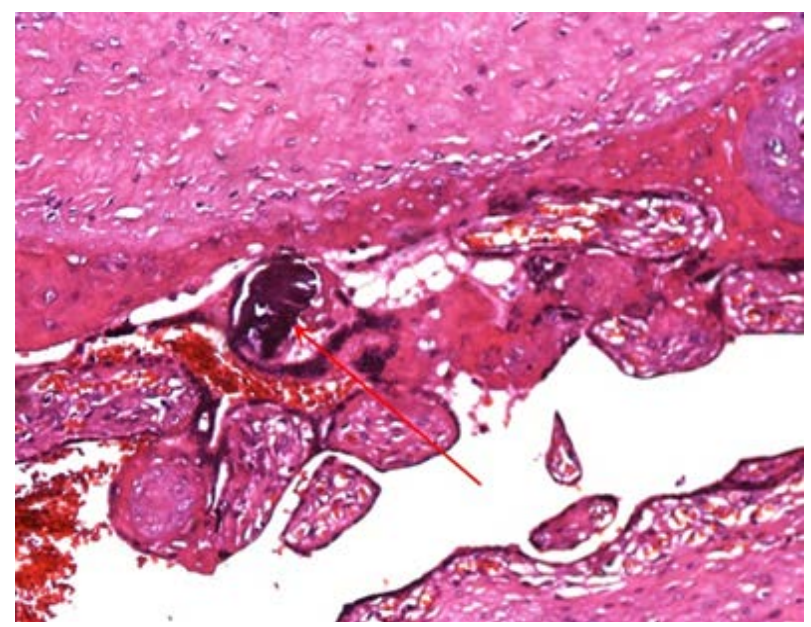

Figure 10. A case of D\&E visualizing focal calcified material deposition (H\&E $100 \mathrm{X}$ ).

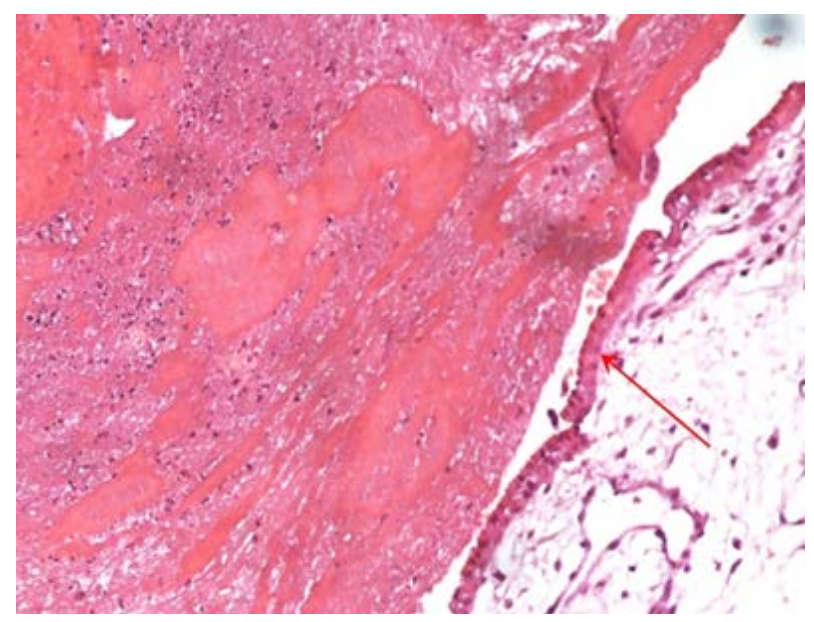

Figure 11. A case of D\&E showing intervillous fibrinoid necrosis with normal villous lining (red arrow) (H\&E $200 \mathrm{X}$ ).

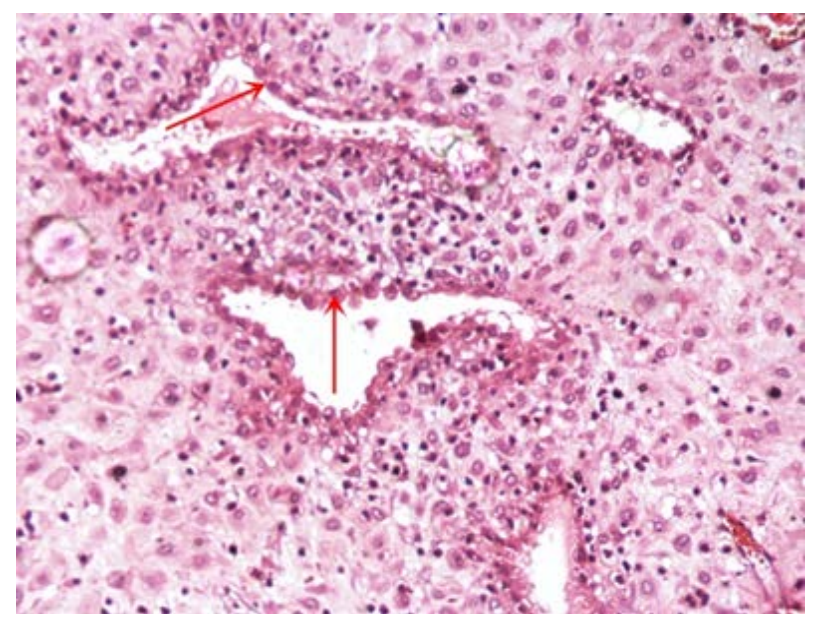

Figure 12. A case of D\&E exhibiting decidual reaction with some secretory changes of endometrial glands (red arrows) (H\&E $100 \mathrm{X})$. 


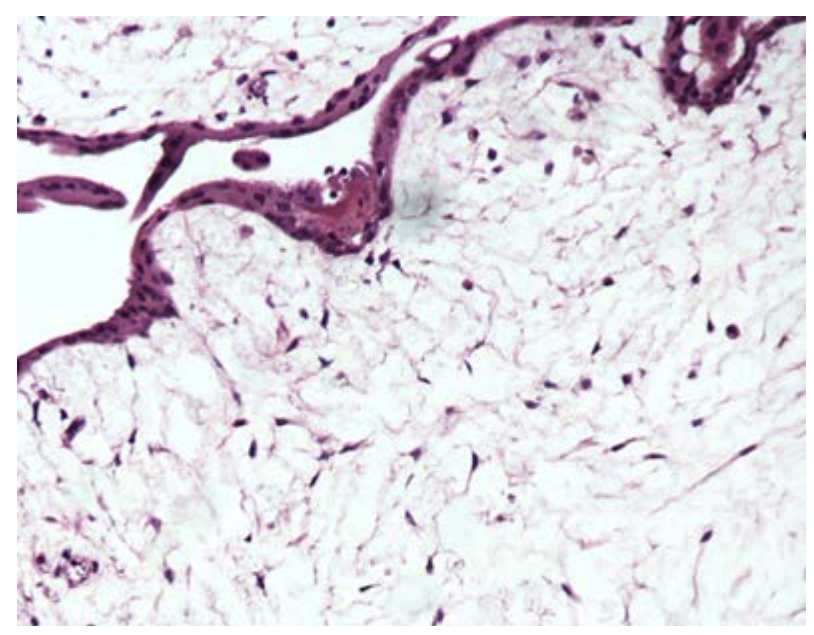

Figure 13. A case of D\&E showing hydropic changes of the villi cores (H\&E $200 \mathrm{X})$.

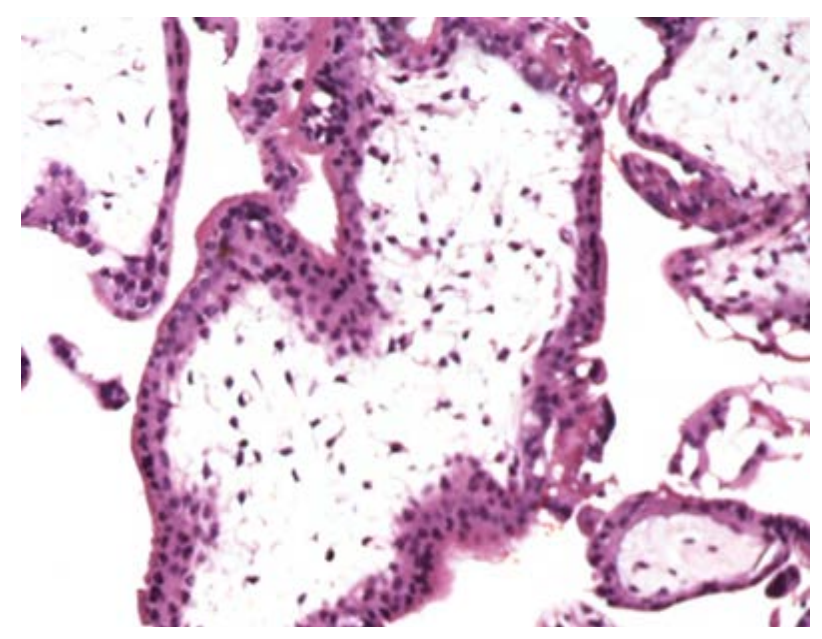

Figure 14. A case of D\&E revealing molar changes with circumferential trophoblastic proliferation (H\&E 200 X).

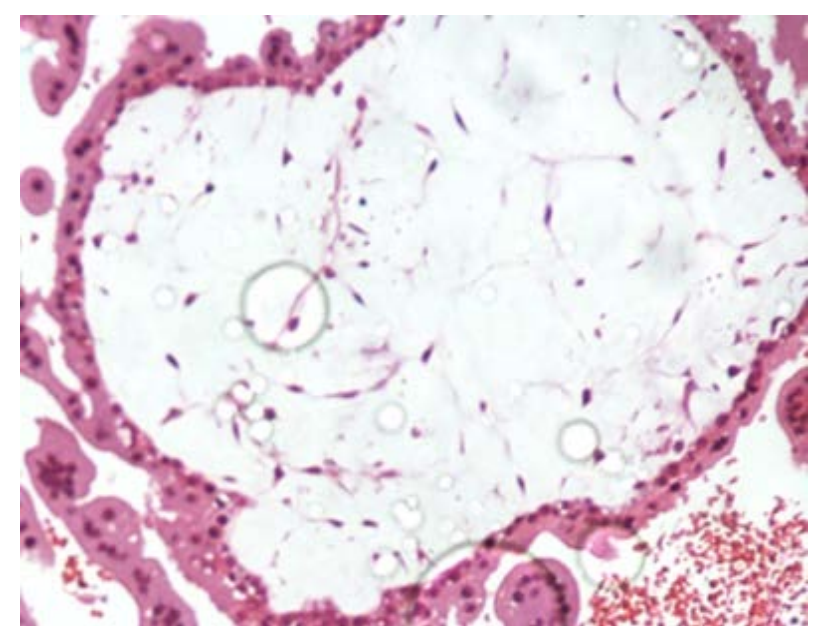

Figure 15. A case of D\&E showing villous distension, core edema and trophoblastic proliferation (H\&E 200 X). 
Table 2. Placental pathologies among all cases studied.

\begin{tabular}{ccc}
\hline Parameters of Placental tissue anomalies: & Number of cases & $\%$ \\
\hline Infarction & 50 & 25 \\
Infections & 20 & 10 \\
Chorioamnionitis & 15 & 7.5 \\
Villitis & 5 & 2.5 \\
Perivillous hemorrhages and fibrin deposition & 15 & 7.5 \\
Chorioangiosis & 5 & 2.5 \\
Calcification & 25 & 12.5 \\
Fibrinoid necrosis & 5 & 2.5 \\
Necrotic villi (ghosts) & 10 & 5 \\
Decidual reaction & 50 & 25 \\
Hydropic changes & 10 & 5 \\
Molar changes & 10 & 5 \\
Total cases & 200 & 100 \\
\hline
\end{tabular}

In our study incomplete abortion seen in the majority of cases that found in $42.5 \%$, this result pass in parallel with a study was done in Jordan University Hospital by [10] who mentioned the highest type of abortion among the studied group was incomplete abortion, 140 patients (48\%). In our cases, spontaneous abortion observed in $25 \%$ among them, whereas incomplete abortion ranked the majority of cases and found in $42.5 \%$ and unfortunately $5 \%$ of cases were related to trauma. A study was performed by [11] they reported 39.7\% had spontaneous abortion at $>20$ weeks gestational age at his institution.

The present study showed an infarction of placentae in 50 cases (25\%). Placental infarcts represent localized areas of ischemic necrosis of villi usually due to diminished maternal perfusion to the intervillous space. These results are in agreement with [12]. Villous infarcts occur in two situations: obstruction of major uterine arteries by thrombosis or remodeling and separation of the placenta from its underlying blood supply due to retroplacental hemorrhage and also in line with [13] [14].

Placental infection was observed in 20 cases (10\%), majority of this pathology was chorioamnionitis (7.5\%), whereas minority was villitis (2.5\%). Chorioamnionitis particularly in a preterm pregnancy can result in premature rupture of membranes and/or premature labor. The present results are in confirmatory with [15] who estimated that $50 \%$ - $60 \%$ of all preterm placentas have evidence of amnionic fluid infection, and also are in confirmatory with [16]-[18]. Additionally, intrauterine infection is clinically a common etiology of spontaneous abortion. Microbiological studies of amniotic fluid have shown that overall rates of infection in spontaneous abortion are $25 \%$ - $40 \%$ as well as approximately $32.5 \%$ of women with preterm onset of labor and over $75 \%$ with premature rupture of membranes have positive amniotic fluid cultures [19].

In addition to the above pathology perivillous hemorrhages and fibrin deposition were seen in 15 cases (7.5\%). This pathology related to break of numerous barriers associated with hemorrhage from the fetal circulation into maternal intervillous space. These results were in line with [20]. Also, this result was in line with [21] they showed that perivillous fibrin deposition was observed in $46.1 \%$ in spontaneous abortions. As well as chorioangiosis was another anomalies that found in 5 cases (2.5\%). This lesion is defined as a diffuse increase in the number of villous capillaries in the terminal villi this result in harmony with [22]. A recent study done by [23] they found chorioangiosis was found in 58 out of 665 cases (8.7\%).

Another pathology that was observed histologically was calcification in the mesenchyme of cotyledons. Calcification was recorded in 25 placentas in a percentage of (12.5\%), calcification occurred due to ischemic hypoxia and degeneration and necrosis that followed by calcium deposition in the necrotic area these results are in agreement of [24] who noted that the placental calcification subdivided by two major groups. The first is relating to "dystrophic" calcification following the same rules in the placenta as it does in other places, in other words, it is calcification of necrotic tissue portions or acidotic areas of decreased circulation. Calcification may just as well occur to particular structures of the placenta, these results are in line with [25] they were found that the calcification caused by nan-bacteria-like particles (NLP) in extracellular matrix of calcified placental tissues.

In the recent study the decidual reaction represent about 50 cases (25\%). Decidual inflammation is limited to the decidua basalis, and defined as diffuse lymphocytic infiltrate of the basal plate or any infiltrate in the decidua 
basalis that includes plasma cells. These results are in agreement with [26] who found that $40 \%$ of preterm placentas from cases of idiopathic preterm labor and $15 \%$ of their control cases had chronic deciduitis.

Also this study revealed hydropic change in 10 cases (5\%) because of loss of the villous vascular supply. The avascular villi are mildly distended with fluid these results are associated with [27] who observed that the avascular villi are mildly distended with fluid and the curettage samples do not contain fetal tissue giving the changes of the so-called blighted ovum.

In our study molar changes were found in 10 cases (5\%), all of them had circumferential trophoblastic proliferation. A study performed by [28] they reported that eight of their 81 patients (9.9\%) had the disease. Additionally, other studies reported complete mole may be ranged in cases $10 \%-20 \%$, and partial mole from $0.5 \%$ $6.6 \%$ [29]-[31].

Finally, regardless the indications of D\&E procedure, it remains the safe one compared with other induction methods and this procedure itself has decreased morbidity for the patient. In the same theme carful microscopic examination of the placenta in D\&E specimens following the abortion can be a useful guide in determining the most important lesions and provide information that helps us in management of current infant and subsequent pregnancies also can influence clinical care by providing knowledge in relation to genetic counseling and family planning.

\section{Acknowledgements}

The authors thank all staff members and technicians of the Pathology Department, Arar Central Hospital, Saudi Arabia for their kind help during the preparation of this study.

\section{Funding}

This work lacked any financial support and was performed on formalin fixed paraffin-embedded blocks in conjunction with the database of patients medical record.

\section{References}

[1] Sadler, T.W. (2012) Fetal Membranes and Placenta. In: Langman's Medical Embryology, 12th Edition, Wolters Kluwer, Philadelphia, 96-101.

[2] Lanir, N., Aharon, A. and Brenner, B. (2003) Haemostatic Mechanisms in Human Placenta. Best Practice \& Research Clinical Haematology, 16, 183-195. http://dx.doi.org/10.1016/S1521-6926(02)00098-1

[3] Fox, H. (1999) Development of Placenta and Membranes. In: Dewhursts, J., Deswiet, M. and Chamberlain, G., Eds., Basic Sciences in obstetrics and Gynecology, Churchill Living Stone, Philadelphia.

[4] Vijay, V. (1994) Joshi. Handbook of Placental Pathology. 2nd Edition, IGaku-Shoin, New York.

[5] Christopher, P.C. (2004) The Female Genital Tract. In: Cotran, R.S., Kumar, V. and Collins, T., Eds., Pathologic Basis of Disease, 7th Edition, WB Saunders, Philadelphia, 1079-1080.

[6] Roberts, D.J and Oliva, E. (2006) Clinical Significance of Placental Examination in Perinatal Medicine. Journal of Maternal-Fetal and Neonatal Medicine, 19, 255-264. http://dx.doi.org/10.1080/14767050600676349

[7] Sun, C.J., Revell, V.O., Belli, A.J. and Viscardi, R.M. (2002) Discrepancy in Pathologic Diagnosis of Placental Lesions. Archives of Pathology \& Laboratory Medicine, 126, 706-709.

[8] Ernst L.M., M.D., Gawron L., and Fritsch M.K. (2013) Pathologic Examination of Fetal and Placental Tissue Obtained by Dilation and Evacuation. Archives of Pathology \& Laboratory Medicine, 137, 326-337. http://dx.doi.org/10.5858/arpa.2012-0090-RA

[9] Fox, M.C. and Krajewski, C.M. (2013) Cervical Preparation for Second-Trimester Surgical Abortion Prior to 20 Weeks' Gestation: SFP Guideline \#2013-4. Contraception, 89, 75-84.

[10] Fram, K.M. (2002) Histological Analysis of the Products of Conception Following First Trimester Abortion at Jordan University Hospital. The European Journal of Obstetrics \& Gynecology and Reproductive Biology, 105, 147-149. http://dx.doi.org/10.1016/S0301-2115(02)00155-0

[11] Hackney, D.N., Tirumala, R., Salamone, L.J, Miller, R.K. and Katzman, P.J. (2013) Do Placental Histologic Findings of Chorion-Decidual Hemorrhage or Inflammation in Spontaneous Preterm Birth Influence Outcomes in the Subsequent Pregnancy? Placenta, 35, 58-63.

[12] Petersen, O.M., Heller, D.S. and Joshi, V.V. (2006) Handbook of Placental Pathology. Taylor and Francis, Oxford.

[13] Katzman, P.J. and Genest, D.R. (2002) Maternal Floor Infarction and Massive Perivillous Fibrin Deposition: Histolo- 
gical Definitions, Association with Intrauterine Fetal Growth Restriction, and Risk of Recurrence. Pediatric and Developmental Pathology, 5, 159-164. http://dx.doi.org/10.1007/s10024001-0195-y

[14] Sebire, N.J., Backos, M., El Gaddal, S., Goldin, R.D. and Regan, L. (2003) Placental Pathology, Antiphospholipid Antibodies, and Pregnancy Outcome in Recurrent Miscarriage Patients. Obstetrics \& Gynecology, 101, 258-263. http://dx.doi.org/10.1016/S0029-7844(02)02385-2

[15] Redline, R.W. (2012) Inflammatory Response in Acute Chorioamnionitis. Seminars in Fetal \& Neonatal Medicine, 17, 20-25. http://dx.doi.org/10.1016/j.siny.2011.08.003

[16] Redline, R., Faye-Petersen, O., Heller, D., Qureshi, F., Savell, V. and Vogler, C. (2003) Amniotic Infection Syndrome: Nosology and Reproducibility of Placental Reaction Patterns. Pediatric and Developmental Pathology, 6, 435-448.

[17] Kraus, F.T., Redline, R.W., Gersell, D.J., Nelson, D.M. and Dicke, J.M. (2004) Placental Pathology. In: Atlas of Nontumor Pathology, AFIP, Washington DC, 75-115.

[18] Benirschke, K.K.P. and Baergen, R.N. (2006) Pathology of the Human Placenta. 5th Edition, Springer, New York.

[19] Goldenberg, R.L., Culhane, J.F., Iams, J.D. and Romero, R. (2008) Epidemiology and Causes of Preterm Birth. Lancet, 371, 75-84. http://dx.doi.org/10.1016/S0140-6736(08)60074-4

[20] Habek, D. (2011) Multiple Intraplacental Hematomas-Kline’s Hemorrhage. Case Report. Acta Clinica Croatica, 50, 423-425.

[21] Sarin, A.R., Kaur, B., Modi, S. and Popli, R. (1993) Histopathological Changes in Placenta in Early Pregnancy Wastage. Indian Journal of Maternal and Child Health, 4, 75-77.

[22] Fox, H. and Sebire, N.J. (2007) Pathology of the Placenta-Major Problems in Pathology, 3rd Edition, Saunders-Elsevier, China.

[23] Soma, H., Murai, N., Tanaka, K., Oguro, T., Kokuba, H., Fujita, K. and Mineo, S. (2013) Angiogenesis in Villous Chorangiosis Observed by Ultrastructural Studies. Medical Molecular Morphology, 46, 77-85. http://dx.doi.org/10.1007/s00795-013-0010-7

[24] Emmrich, P. (1992) Pathology of the Placenta. X. Syncytial Proliferation, Calcification, Cysts, Pigments and Metabolic Disorders. Zentralblatt für Pathologie, 138, 77-84.

[25] Lu, H., Guo, Y.N., Liu, S.N. and Zhang, D.C. (2012) Nanobacteria May Be Linked to Calcification in Placenta. Ultrastructural Pathology, 36, 160-165. http://dx.doi.org/10.3109/01913123.2011.653710

[26] Edmondson, N., Bocking, A., Machin, G., Rizek, R., Watson, C. and Keating, S. (2009) The Prevalence of Chronic Deciduitis in Cases of Preterm Labour without Clinical Chorioamnionitis. Pediatric and Developmental Pathology, 12, 16-21. http://dx.doi.org/10.2350/07-04-0270.1

[27] Szulman, A.E. (1991) Examination of the Early Conceptus. Archives of Pathology \& Laboratory Medicine, 115, 696700.

[28] Berkowitz, R.S., Goldstein, D.P. and Bemstein, M.R. (1985) Natural History of Partial Molar Pregnancy. Obstetrics and Gynecology, 66, 677-681.

[29] Bagshawe, K.D., Lawler, S.D., Paradinas, F.J., Dent, J., Brown, P. and Boxer, G.M. (1990) Gestational Trophoblastic Tumours Following Initial Diagnosis of Partial Hydatidiform Mole. Lancet, 335, 1074-1076. http://dx.doi.org/10.1016/0140-6736(90)92641-T

[30] Rice, L.W., Berkowitz, R.S., Lage, J.M., Goldstein, D.P. and Bernstein, M.R. (1990) Persistent Gestational Trophoblastic Tumor after Partial Hydatidiform. Gynecologic Oncology, 36, 358-362. http://dx.doi.org/10.1016/0090-8258(90)90142-8

[31] Szulman, A.E. (1988) Trophoblastic Disease: Clinical Pathology of Hydatidiform Moles. Obstetrics and Gynecology Clinics of North America, 15, 443-456. 